\title{
Lack of Awareness as Aggravating Factor for the Detrimental Impacts of Hazardous Chemicals: A Review
}

\section{Desta Dirbeba Dinka *}

Department of Chemistry, Dire Dawa University, Ethiopia

*Corresponding author: Desta Dirbeba Dinka, Department of Chemistry, Dire Dawa University, Dire Dawa, Ethiopia, Tel: +251989186439; E-mail: destad24@gmail.com

Received date: June 27, 2018; Accepted date: July 02, 2018; Published date: July 12, 2018

Copyright: () 2018 Dinka DD. This is an open-access article distributed under the terms of the Creative Commons Attribution License, which permits unrestricted use, distribution, and reproduction in any medium, provided the original author and source are credited.

\begin{abstract}
It is a known fact that individuals can possibly become in contact with multitudes of chemicals at workplace, in homes, in outdoor, at indoor and through consumption of food. However, the majority of individuals particularly in developing countries are unaware of toxicities of toxic chemicals and the possible routes of exposure to those chemicals. Although exposure to toxic chemicals is inevitable, lack of awareness exacerbates the incidence of toxic exposure to those chemicals. It is on this account that some classes of hazardous chemicals and sources exposure to them are briefly reviewed in this paper. Furthermore, the extent awareness of individuals about risks associated with hazardous chemicals is reviewed in far more detail manner with particular regard to developing countries with ultimate goal of making the problem more noticeable to concerned authorities and international organizations.
\end{abstract}

Keywords: Hazardous chemical; Lack of awareness; Toxic exposure

\section{Introduction}

Chemicals are essential to life, and their benefits are widespread and well-recognized. However, chemicals also pose a broad range of potential adverse effects including health hazards, physical hazards and environmental hazards [1]. A hazard is a potential source of harm or an adverse health effect on persons [2]. The hazards of chemicals stem from their inherent flammability, explosiveness, sensitizablity, toxicity, carcinogenicity, corrosiveness, and radioactivity [3]. Hazardous chemical is as any chemical that presents a physical hazard or a health hazard. Health hazard means a chemical for which there is significant evidence based on at least one study conducted in accordance with established scientific principles that acute or chronic health effects may occur in exposed employees [4]. Chemicals which are carcinogens, reproductive toxins, irritants, corrosives, sensitizers, hepatotoxins, nephrotoxins, immunotoxin, and neurotoxins are health hazards [4]. The works of Banerjee et al. [6], Anetor et al. [7], Eugine et al. [8], Soderland et al. [9] and Singh [10] indicate that toxic xenobiotic are immunotoxin, hepatotoxins, nephrotoxins, reproductive toxins and neurotoxins. As a result xenobiotic and chemicals that present health hazards (also simply called health hazards) are alternatively used in this paper. According to ILO [4], hazardous chemicals that are currently of great concern for the environment, and human health are the heavy metals such as lead, cadmium and mercury; endocrine disrupting chemicals such as some insecticides and fungicides; Persistent Organic Pollutants (POPs) and atmospheric pollutants such as oxides of sulphur, nitrogen and carbon dioxide. Polybrominated diphenyl ethers, polychlorinated dibenzodioxins, polychlorinated dibenzofurans and Polychlorinated Biphenyls (PBCs) congeners are also hazardous chemicals $[8,11,12]$. All these aforementioned chemicals fall in the domain of xenobiotic definition. Xenobiotics are any biologically active chemicals of synthetic origin many of which are capable of compromising human health [13]. Through ingestion of drinking water and food, and inhalation of indoor as well as outdoor air the general public can come in contact with toxic chemicals like pesticides, Polycyclic Aromatic Hydrocarbon (PAHs), Persistent Organic Pollutants (POPs), fertilizers, arsenic, fluoride, nitrate, cyanide, industrial solvents, petroleum products, and others $[13,14]$. Toxic heavy metals, pesticides and POPs are environmental xenobiotic known for their neurotoxic ant nature $[9,10,15,16]$. Many environmental xenobiotic are also capable of causing mitochondrial dysfunction which is partly responsible for pathophysiology of agerelated chronic diseases such as metabolic syndrome, diabetes, coronary artery disease, acute coronary syndrome, stroke, Alzheimer's disease, Parkinson's, depression and cancer [17]. All toxic heavy metals including $\mathrm{Pb}, \mathrm{Cd}, \mathrm{Hg}, \mathrm{As}$ and $\mathrm{Pd}$ are potentially known as nephrotoxicants $[9,18]$. Janssen [19] pinpointed that many pesticides known to cause birth defects or other reproductive harm. The author's study revealed workers exposed to pesticides have increased risks of miscarriage, infertility, and a variety of birth defects. Poor semen quality of worker in state of California men has also been associated with pesticide exposure [19]. Individual who works in manufacturing industry, mining area can potentially be exposed to toxic levels of pesticides, benzene, heavy metals, solvents and suspended particulate matter through occupational exposure [14]. There is growing evidence that unregulated pesticide use and lack of enforcement mechanisms are increasing the risk of adverse health effects and environmental contamination, particularly in developing countries. Although their uses are only $25 \%$ of the world's pesticides, developing countries experience $99 \%$ of the deaths linked to pesticides due to lack of awareness and regulation [20].

\section{Some classes of hazardous chemicals and their adverse impacts}

Polycyclic aromatic hydrocarbons (PAHs): PAHs are a group of chemicals that are formed during incomplete burning of coal, oil, gas, wood, garbage or other organic substances such as tobacco and charbroiled meat [21]. A number of anthropogenic sources that introduces PAHs to environment have been identified. Exhaust gases 
from vehicles, residential wood and coal burning, power generation, steelworks, coke ovens, aluminum production, cement kilns and oil refineries are among such sources [22]. Benzo[a] pyrene, chrysene, benz[a]anthracene, benzo[b]fluoranthene, and dibenz [a,h] anthracene are possible carcinogens in the class of PAHs [14,21]. Thus, inhalation of indoor air is the potential sources of PAHs to which general public can be easily exposed. Although it is difficult to avoid exposure to PAHs on individual basis, awareness of toxicity of such chemicals and the possible sources of exposure to them can significantly minimize toxic exposure to the chemicals. Exposure to these chemicals from tobacco, charbroiled meat, and burning of wood and coal can be best minimized if awareness is there. However, individuals particularly those living in developing countries are almost totally unaware of the potential toxicity of PAHs, let alone sources of exposure to these chemicals. For instance, charbroiled meat is favorite food in many places in Ethiopia. However, it is hard to find one in hundred who is aware of possible exposure to these chemicals when having such meals.

Persistent organic pollutants (POPs): POPs are defined as highly toxic compounds, persistent in the environment, able to migrate in food chains and have high bio-accumulation potential [8]. The Stockholm Convention on POPs coined "The Dirty Dozen" to 12 Chemicals. These 12 chemicals include eight pesticides (DDT, aldrin, chlordane, dieldrin, endrin, heptachlor, mirex, and toxaphene); two industrial chemicals (PBCs and hexachlorobenzene); and two unintended by-products, dioxins and furans [12]. Because of persistence, bioaccumulation, and lipophilic nature, POPs are often ubiquitous in the environment and thus they can be detected even in pristine areas [13]. The use of these dirty dozen is banned or highly restricted in many countries because of their inherent toxicities. POPs are toxic causing adverse health effects such as birth defects, damage to immune, endocrine and respiratory systems, and critical organs [12].

Dioxins: The name "dioxins" is often used for the family of structurally and chemically related Polychlorinated Dibenzo Para Dioxins (PCDDs) and polychlorinated dibenzofurans (PCDFs). Certain dioxin-like polychlorinated biphenyls with similar toxic properties are also included under the term "dioxins" [23]. It is thus a collective term for PCDDs, PCDFs and co-planar PCBs (JME, 2012). Polychlorinated dibenzo-p-dioxins (PCDDs), Polychlorinated dibenzofurans (PCDFs) and co-planar polychlorinated biphenyls are compounds in which 1-10 chlorine atoms are attached to one of three different structures containing two benzene rings [24]. They belong to the so-called "dirty dozen" - a group of dangerous chemicals known as persistent organic pollutants [23]. Dioxins and dioxin-like substances are persistent organic pollutants covered by the Stockholm Convention on Persistent Organic Pollutants; they can travel long distances from the emission source and can bioaccumulate in food-chains [25].

PCDDs and PCDFs are by-products of industrial processes including the manufacture of chlorophenols and phenoxy herbicides, chlorine bleaching of paper pulp and smelting [25]. Although dioxins are not produced commercially, they are sometimes formed as byproducts of chemical processes like incineration of chlorinecontaining wastes, petroleum refining catalyst regeneration, and during the production of some halogenated organic chemicals $[24,26]$. They can also naturally be produced from the incomplete combustion of organic material by forest fires or volcanic activity [27]. However, unintentional anthropogenic activities are the dominant contributor of our burdens of dioxins is found throughout the world in the environment and they accumulate in the food chain, mainly in the fatty tissue of animals. More than $90 \%$ of human exposure is through food, mainly meat and dairy products, fish and shellfish [23]. Thus in general population, low- level dioxin contamination of foodstuffs is the major contributor to the body burden of dioxins [26]. In Japan the main source of dietary intake of dioxins is fish while in Europe and the United States the main sources are meat and dairy products.

Dioxins have been shown to be carcinogenic in animals and humans. In humans excess risks were observed for all cancers without specific cancer predominating [28]. Dioxins are highly toxic and can cause reproductive and developmental problems, damage the immune system, interfere with hormones; cause thyroid and nervous systems disorder $[8,11]$. Human exposure to dioxins and dioxin-like substances has been associated with a range of toxic effects including immunotoxicity, reproductive and developmental toxicity, dermal toxicity, carcinogenicity, and neurodevelopmental effects, and changes in thyroid and steroid hormones and reproductive function [24,25]. The degree of toxicity of dioxins varies from compound to compound. Among all dioxins, the tetra chlorinated dibenzo-p-dioxin with chlorine atoms attached in the 2, 3, 7 and 8 positions (2, 3, 7, 8-TCDD) is known to possess the highest toxic potency [29]. The EPA has determined that TCDD is a possible human carcinogen [27]. According to WHO [23], TCDD is amongst the world's most toxic substances. In animal experiments, TCDD has been shown to affect the reproductive and immunological systems and also to affect neurodevelopment. Results of studies about effects of TCDD in human are inconsistent [28].

Although exposure to dioxins is inevitable, trimming fat from meat and consuming low fat dairy products may decrease the exposure to dioxin compounds [23]. Indeed, consuming low fat food is not only advisable to minimize exposure to dioxins but also to all fat-soluble (lipophilic) POPs. This is the very reason why many countries recommend pregnant and children to avoid fish and other food items of high fat content in their diet. However, the awareness of the general public in developing countries about the adverse health impacts of POPs is very low or none at all. Consequently, the Dirty Dozen are silently at work endangering or claiming the life of many people.

Polychlorinated Biphenyls (PCBs): PCBs are synthetic chlorinated hydrocarbon compounds that consist of two benzene rings linked by a single carbon-carbon bond with from 1 to all 10 of the hydrogen atoms replaced with chlorines [30]. PCBs are a family of 209 compounds composed of attached benzene rings with varying numbers and locations of chlorine atoms. They have been produced commercially by chlorination of biphenyl with anhydrous chlorine under heated reaction conditions and in the presence of a catalyst [24]. PCBs were previously manufactured for use as dielectric fluids in larger-scale electrical products such as transformers and capacitors, in heat transfer and hydraulic systems [25]. They have been used in capacitors, transformers, plasticizers, surface coatings, inks, adhesives, flame retardants, pesticide extenders, paints, microencapsulating of dyes, carbonless duplicating paper, and immersion oils for microscopes [24]. Globally, PCBs have been found in ambient air at concentrations from 0.002 to $15 \mathrm{ng} / \mathrm{m}^{3}$ of total-PCB of which dioxin-like PCBs are thought to only constitute a minor fraction. In industrial areas, levels are expected to be much higher [24]. Human studies have identified associations between exposure to PCB mixtures and adverse immunological, reproductive, and dermatological effects and cancer. Immunotoxicity and neurotoxicity of PBCs to experimental animals has been well-known [30]. Chronic exposure of humans to PCBs at low levels can cause alteration to liver enzymes, rashes, acne, 
developmental, mental and behavioral problems, immune suppression, and possibly cancer.

Cleaning and personal care products: Several chemicals present in some household and industrial cleaning products have been identified as asthma triggers or are known to aggravate existing respiratory symptoms. These chemicals include monoethanolamine, ammonium quaternary compounds, chlorhexidine and several others [31].

Nail products are known to contain toxic chemicals such as dibutyl phthalate, toluene and formaldehyde. Dibutyl phthalate and toluene are known as developmental toxins while formaldehyde is a known carcinogen. Guo et al. collected twenty five nail product samples from six distributors in California and analyzed their ingredients. Their finding showed that unreliability of product designations and labeling for nail coatings as significant number of the products were found to contain the three chemicals. The nail salon owners, practitioners and consumers need to have the ability to identify hazardous constituents in the products they use [32]. Beyond man-made chemicals, cosmetics also contain natural toxins. As mentioned by Bucheli and co-workers more than one thousand natural substances were believed to be contained in cosmetics as ingredients, out of which $27 \%$ are classified as hazardous chemicals. Natural compounds used as ingredient of cosmetics pose a risk both to human health and to the aquatic environment [5]. Phthalates are used in lotions as moisturizing agents since they are able to produce softer skin and able to penetrate the skin that allows the product to infuse softness deeper in the skin. As result, phthalates are used in a large variety of personal care products including body lotion, hand lotion, hair products, deodorants, nail polish, lipsticks, and in the fragrances used in personal care products as well as colognes and perfumes [33]. However, phthalates, particularly dibutyl phthalate (DBP) and diethylhexyl phthalate have potential health risks in impairing fertility and causing developmental toxicity in humans. DBP is suspected as endocrine disruptor as it interferes with hormonal function and as toxic to reproduction [34]. It is on this basis that European Union bans DBP in cosmetics as well as in childcare articles and toys. Parabens are another group of chemicals used as preservatives and antimicrobials in a variety of consumer products including cosmetics to help preserve the shelf life of the product [34]. Parabens are suspected of interfering with hormone function. They can mimic estrogen, the primary female sex hormone and may also interfere with male reproductive functions [34].

The aim of this paper is not to discuss the use of those chemicals, but the associated health impacts which is worsen by lack of awareness of the hazards of such chemicals as well as the potential routes of toxic exposure to them. In developing countries, it is hard to find people who are aware of the availability of potentially hazardous chemicals in personal care products. Cautious and sensible use of personal care products is possible only when users recognize the possible presence of hazardous substances in such products. There is no doubt that repeated exposures without necessary precaution to personal care products containing hazardous substances cause adverse health impacts.

\section{Routes of Exposures to Hazardous Chemicals}

Human beings are exposed to toxic substances directly through the daily use of numerous chemical products such as food additives, cleaning agents, cosmetic products, pesticides, paints and consumer products like electronic goods, furniture, floor and wall linings and construction materials [11]. Human exposure to toxic chemical occurs through occupational exposure, exposure to contaminated products, environmental exposure to toxic waste, inhalation of contaminated air and dust, food intakes and dermal exposure [14]. According to Joshua [35], the three major routes of human exposure to xenobiotic are absorption through skin, oral ingestion, and nasal inhalation. Thus, the main modes of entry of chemicals into the body are inhalation, ingestion and absorption. An individual may be exposed to chemicals in the form of solids, liquids, mists, aerosols, dusts, fumes, vapors or gases in any combination. Gases, vapors, mists, dusts, fumes and aerosols can be inhaled or absorbed through skin. Ingestion is rare although possible as a result of poor personal hygiene, subconscious hand-to-mouth contact or accidents [3]. Skin contact and inhalation are, however, the most likely ways individuals may be exposed to hazardous substances [36]. The effect of exposure may be acute showing immediately after the exposure or chronic showing only after prolonged use [35]. The severity of any effect from exposure to pesticide depend on the dose, the route of exposure, how easily the pesticide is absorbed, the type of effect of the pesticides and its metabolites, the accumulation and persistence in the body and lastly, the gender, age, and health status of the individual [35]. Special attention is paid to long-term exposures to low doses of chemicals in consumer products, food items and drinking-water [11]. An exposure to a specific chemical in relatively low concentrations over a period may result in chronic effects. At higher concentrations, the effects may be acute [3]. The acute effects of chemical exposures based on a single exposure have been broadly recognized as compared to those that result from repeated minor exposures over time, because of the immediate associated symptoms. Chronic exposures, however, have no immediate associated symptom which makes difficult linking of chronic exposure to associated health problems [1]. This is the reason why many chemicals are called Silent Killers. Acute effects are quickly observed and could be swiftly contained and remedied, chronic effects are difficult to recognize. Hundreds of thousands of people could therefore have suffered irreparable damages before these insidious effects are noticed [25]. The ILO estimated that nearly 440,000 people throughout the world died as a result of occupational exposure to hazardous substances in 2005 . Over 70 per cent of this total figure, or nearly 315,000 people, died of cancer [25].

\section{Awareness of Hazards of Chemicals}

About three decades ago, Scudder et al. studied public attitudes and awareness concerning household hazardous chemicals [37]. They revealed that people lacked the expected knowledge about hazardous chemicals. The authors strongly recommended that the only solution to such problem is education and awareness-raising campaign. However, up to now, there have been no visible strides in a sensible people's awareness' creation that saves individuals from the detrimental effect of chemicals. Selin [38] mentioned that many people particularly in developing countries are in a multitude of exposure to hazardous chemicals at their workplace or through use of common household products. According to the author, the main reason attributable to such problem is a lack of knowledge about potential toxicity of xenobiotic and a failure to take proper handling practices. More impressive the result was the work of Lunar and co-workers. Lunar et al. [39] assessed the awareness of Filipino students in a college about hazards and risks of laboratory chemicals. Their study showed that the students exhibit poor understanding of the matter. The result is very alarming. If science students working in laboratory are unaware of the toxicity and risk associated with laboratory chemicals they are working with, it would not be difficult to guess the serious of the problem when the 
general public considered. This result is not limited to Philippines, it also holds true in almost all developing countries where chemical regulations, health and safety standards are lax. Though the silent killers (i.e., toxic xenobiotic with chronic effects) are busy with their work, the majority of people particularly living developing countries are unaware of them. The silent killers have claimed many thousands of people all over the world and are still claiming sizable number of population. Economic Commission for Africa (ECA) revealed that awareness of possible risks posed by chemicals is low among major segments of African population which is further complicated by the general lack of reliable data and information on toxicity and safe use practices for chemicals [40]. Selin [38] pinpointed that thousands of deaths due to toxic chemical mainly arises due to lack of knowledge about their potential toxicities. Knowledge potential toxicities of chemicals alone is not sufficient, knowledge of potential sources and proper handling practices are also critical. According to Tyrkko et al. [41], lack of knowledge on how to handle chemicals is among many factors contributing high risks of chemical poisoning. In fact, unawareness in taking proper protective measures in part arises from the lack of knowledge of potential toxicity of hazardous substances. Once the awareness is there, it is possible to reduce the risks. Lack awareness about potential toxicity of hazardous substances, routes of exposure and proper handling practices in developing is aggravated by many factors. Poor chemical regulation and safety standards are one of such factors. According to ILO [42] and Joshua [35], health and safety standards in developing countries are often lax or poorly enforced with severe consequences on the health of citizens. There is a general lack of knowledge about risks with chemicals, how to use them and dispose of them safely.

Very recently, Luca et al. [43] analyzed human perception regarding the relation between environment and health to gauge public awareness on the consequences of chemical exposure. Their findings indicated that people of East-central Europe believe that home and neighborhood can be managed more easily than the wider natural environment. This clearly shows the general public is unaware of the harmful effects of cleaning products in homes; pesticides used in their immediate vicinity and potentially harmful exposure to chemicals through food, air and water. This lack of information about the impact of chemicals on health is evident both in developed and developing countries though much serious in developing countries due to several reasons. Several recent studies have demonstrated that knowledge of the general public about chemical hazards and risks associated with the use of chemicals continues to be very limited. Thus, it should be of a serious concern to researchers, governmental institutions, international organizations and non-governmental organization working on related matters.

Joshua [35] mentioned several major factors that lead to a preponderance of adverse health impacts associated with pesticide use in developing countries. According to Joshua, lack of adequate information, knowledge, and awareness of the inherent dangers of pesticides is among such factors. Shafiei et al. [44] pointed out that though Asian rice is highly suspected of arsenic contamination; there is the lack of public awareness about the adverse health effects of toxic metals in rice. The authors opined that increased risk perception, and subsequently, increased public awareness about the adverse effects of toxic metals are critical in face of exceedingly increasing risk exposure with toxic xenobiotic like heavy metals.

Although lack of awareness about potential toxicity of xenobiotic, possible routes of exposure to them and proper handling practices seems virtually global; but it is very serious in developing countries. There is lack of information and knowledge about hazardous properties of chemical substances among the general public particularly in developing countries [11]. Many people, particularly in developing countries are exposed to a multitude of hazardous chemicals at their workplace or through use of common household products. In many cases, this is because of a lack of knowledge about chemical risks and/or a failure to take basic protective measures [38]. Increased risks of exposure to toxic and hazardous chemicals predominantly affect the poor who routinely face such risks because of their occupation and poor living standards [45].

\section{Challenges of Developing Countries in Awareness Creation}

Challenges of chronic burdens of diseases in developing countries, however, are not only due to lack of knowledge about toxic chemicals. There are several contributing factors as well. Konradsen et al. clearly stated that weak or a totally absent legislative framework in the use of chemicals is among the major reasons for the high incidence of toxic poisoning in developing countries [46]. Even all over the world, the scientific regulations pertaining to synthetic chemicals are suspected to be rather lax, and skewed more towards protecting the manufacturers' profit than the consumers' health [35].

Furthermore, developing countries often lack adequate technical, financial, and human resources to initiate more effective risk-reduction measures [38,47]. Developing countries typically lack access to best available techniques and best environmental practices for limiting emissions of by-products from industrial manufacturing, combustion processes, and waste management [38].

The majority of people in developing countries live in rural areas with low or no education levels [48]. These illiterate people are unable to follow written instructions on chemical product packages and unable to read to access information [49]. Thus, awareness reaction will remain challenge in such areas.

Another aggravating factor in developing countries is that health and other authorities themselves are more likely unaware of the magnitude of the problem of toxic exposures as they are overwhelmed by other health priorities such as infectious diseases. Consequently, the burden imposed by xenobiotics' toxicities on the public health system has not been fully recognized [50].

Most African countries still lack institutions and facilities to monitor key chemicals in the environment, and hence develop appropriate control strategies to prevent adverse impacts on human health and the environment [40]. Kamil [36] explicitly explained that the reason for the lack of awareness of some very essential aspects of handling of hazardous chemicals is the absence of a formal institution for management and monitoring chemicals in many countries [36]. Selin [38] strongly opined that public authorities must find better ways of integrating scientific work with decision making so as to effectively expand risk assessments and regulations. The challenge here is that a domestic risk assessment on individual chemicals is very poor or nonexistent in some developing countries.

Furthermore, the presence large size informal economy, in developing countries, which works outside the purview of government, exacerbates the problem. This sector of economy is dominated by small and often unorganized businesses that produce chemical-containing consumer and industrial products [40]. On the top of this, scientific 
work on identifying and evaluating chemical risks is still young globally [38]. Some western countries, however, do have institutions that proactively monitor data and vigilantly detect and responds to any threats to human health resulting from exposure to chemicals by offering expert advice, toxicological exposure and risk assessment, counseling about protective measures, and informing the public and decision-makers about the threats and how to avoid them [11].

But still there a big unsolved problem regarding chemical management and monitoring on global basis. Presence of scant data on emissions, environmental dispersion, and ecosystem and human health effects of most chemicals [38]. Precise and reliable data on the number of existing natural or man-made chemical substances, the quantities used and produced and hazard assessment data are difficult to find, often outdated and conflicting [4].

On account of the aforementioned problems and several others, World Health Organization projects that the burden of chronic disease partly caused by toxic substances in developing countries will outweigh the burden from infectious disease by 2020 [51]. Since World Summit on Sustainable Development in 2002, governments of developed countries have showed their commitments to sound management of chemicals to assure that chemicals are used and produced in ways that lead to the minimization of significant adverse effects on human health and the environment by 2020 [14]. However, the burden of diseases due hazardous substances we have been experiencing is evidencing that the goal has not been reached. Exposure to toxic substances is an important contributor to chronic disease along with other factors. On this account, it was emphasized that primary prevention of exposures to toxic substances is one big measure for alleviating this global pressing issue. Raising awareness, increasing knowledge and changing attitudes of individuals or groups about toxic chemicals are among such measures [49]. Lack of information and education often results in people ignoring or neglecting simple measures that could help to prevent the toxic effects of chemicals. As a result, a large number of poisoning cases result from human negligence, lack of awareness and ignorance, all of which could be avoidable [48,52].

Thus creating awareness about toxicity, safety practices and possible route of exposure to hazardous chemicals has paramount importance in reducing incidence of unintentional, intentional and occupational toxic exposure occurring in home, at outdoor, indoor environment and the workplace [49-55].

\section{Conclusion}

It is known that everybody is in contact with chemicals even on daily basis due to occupational exposure, nasal inhalation from atmosphere, absorption through skin, ingestion through food items and water, exposure to cleaning products and personal care products. However, the knowledge of general population about toxicities of toxic substances, routes exposure to them and proper handling practices particularly in developing countries is very poor. When awareness of inherent toxicities of toxic chemicals is poor or non-existent, individuals recognize toxic substances as 'toxic' if only the chemicals would have immediate adverse action on them. In nutshell, it means that they are ignorant of the chronic effects of the chemicals. In such conditions, the silent killers are at busy work when they victims fall prey to them ignorantly.

There several obstacles and exacerbating factors in awarenessraising in developing countries. Absence of legislative framework concerning chemical safety and regulation standards; lack adequate technical, financial and human resources to initiate effective riskreduction measures; illiteracy of citizens in rural areas with low or no education; public authorities' unawareness of magnitude of toxic exposure problems, and lack institutions to monitor chemicals are among such obstacles. If these things continue unsolved, it is not hard to predict that burden of chronic diseases due to toxic chemicals in developing countries will be seriously alarming, and will silently claim more and more individuals many times greater than it is claiming now. Consequently, international organizations like WHO, ILO, FAO, UNICEF and others are strongly recommended to put more pressures and take more measures to safeguard the lives of many particularly in Africa.

\section{References}

1. International Labor Organization (2014) Safety and Health in the Use of Chemicals at Work: World Day for safety and health at work. April 2014.

2. Vitharana VP, De Silva GS, De Silva S (2015) Health Hazards, Risk and Safety Practices in Construction Sites-A Review Study. Engineer 48: 35.

3. Carson P, Mumford C (2002) Hazardous Chemicals Handbook. 2nd edn. Linacre House, Jordan Hill, Oxford OX2 8DP, England.

4. International Labor Office (2007) Background information for developing n ILO policy framework for hazardous substances. Geneva, 2007.

5. Bucheli TD, Strobel BW, Hansen HB (2018) Personal Care Products Are Only One of Many Exposure Routes of Natural Toxic Substances to Humans and the Environment. Cosmetics 5: 1-11.

6. Banerjee BD, Chakraboti A, Suke SG, Ahmed RS, Tripathi AK (2008) Xenobiotic-induced Immune Alterations: Implications in Health and Disease. Indian Journal of Biochemistry and Biophysics 45: 7-15.

7. Anetor JI, Anetor GO, Iyanda AA, Adeniyi FAA (2008) Environmental Chemicals and Human Neurotoxicity: Magnitude, Prognosis and Markers. African Journal of Biomedical Research 11: 1-12.

8. Eugine M, Vincent T (2016) Prevalence of Persistent Organic Pollutants in Blantyre-Malawi. American Journal of Environmental Protection 4: 61-66.

9. Soderland P, Lovekar S, Weiner DE, Brooks DR, Kaufma JS (2010) Chronic Kidney Disease Associated With Environmental Toxins and Exposures. Advances in Chronic Kidney Disease 17: 254-264.

10. Singh N, Gupta VK, Kumar A, Sharma B (2017) Synergistic Effects of Heavy Metals and Pesticides in Living Systems. Frontiers in Chemistry 5: 1-9.

11. World Health Organization (2016) Chemical Safety and Protection of Human Health: The Slovenian Experience, Copenhagen, Denmark.

12. World Bank (2001) Persistent Organic Pollutants and the Stockholm Convention: A Resource Guide Prepared by Resource Futures International for the World Bank and CIDA.

13. Jaffe R (2005) Xenobiotics: Managing Toxic Metals, Biocides, Hormone Mimics, Solvents and Chemical Disruptors.

14. Pruss-Ustun A, Vickers C, Haefliger P, Bertollini R (2011) Knowns and unknowns on burden of disease due to chemicals: a systematic review 10 : $1-15$.

15. Garcia FP, Ascencio SC, Oyarzun JG, Hernandez AC, Alavarado PV (2012) Pesticides: classification, uses and toxicity, Measures of exposure and genotoxic risks. Journal of Research in Environmental Science and Toxicology 1: 279-293.

16. Rosas LG, Eskenazi B (2008) Pesticides and child neurodevelopment. Curr Opin Pediatr 20: 191-197.

17. Ozaydin FN (2017) Xenobiotics and Chronic disease. Journal Toxicology 1: 1-2.

18. Sarah E, Orr SE, Bridges CC (2017) Chronic Kidney Disease and Exposure to Nephrotoxic Metals-review. International Journal of Molecular Sciences 18: 1-35. 
19. Janssen S (2006) Chemical Exposure and Chronic Disease. Science Fellow. Natural Resources Defense Council, IPEN side event at IFCS, Budapest, September 25: 2006.

20. United Nations Children's Fund (2018) Understanding the Impacts of Pesticides on Children: A discussion paper. United Nations Children's Fund, January 2018.

21. Mumtaz M, George J (1995) Toxicological Profile for Polycyclic Aromatic Hydrocarbons Agency for Toxic Substances and Disease Registry Atlanta. Georgia.

22. Essumang DK (2013) Environmental Xenobiotics: PAHs in Soil (Heavy Metals), Indoor Air and Water Environment. Case Studies of Ghana and Denmark. Luma Print, 6700 Esbjerg.

23. World Health Organization (2016) Dioxins and their effects on human health.

24. Larsen JC (2013) Polychlorinated dibenzo-p-dioxins, dibenzofurans and biphenyls: Evaluation of health hazards and estimation of a quality criterion in soil. Danish Environmental Protection Agency Environmental Project.

25. World Health Organization (2010) Exposure to dioxins and dioxin-like substances: a major public health concern. Geneva, Switzerland.

26. Orloff KG, Hewitt D, Metcalf S, Kathman S, Lewin M, et al. (2001) Dioxin exposure in a residential community. Journal of Exposure Analysis and Environmental Epidemiology 11: 352-335.

27. Agency for Toxic Substances and Drug Registry (1998) Public Health Statement chlorinated dibenzo-p-dioxins.

28. Kogevinas M (2001) Human Health Effects of Dioxins: Cancer, Reproductive and Endocrine System Effects. Human Reproduction Update 7: 331-339.

29. European Chemical Agency (2012) Communication on the safe use of chemicals: Study on the Communication of Information to the General Public. Helsinki, Finland.

30. World Health Organization (2003) Polychlorinated Biphenyls: Human Health Aspects.

31. Gorman A (2007) The potential hazards of chemicals in household cleaning products and their association with asthma and reproductive harm. A Report by Women's Voices for the Earth.

32. Guo DF, Batarseh P, Wong J, Raphael D (2012) Summary of Data and Findings from Testing of Limited Number of Nail Products, EPA, California.

33. Paulsen L (2015) The Health Risks of Chemicals in Personal Care Products and their Fate in the Environment Chemistry Honors Papers 15.

34. David Suzuki Foundation (2010) The "Dirty Dozen" Ingredients Investigated in the David Suzuki Foundation Survey of Chemicals in Cosmetics, Canada.

35. Joshua O (2016) Pesticides Use and Health in Nigeria. Ife Journal of Science 18: 981-990

36. Kamil N (2016) Hazardous Drug Handling Awareness among Faculty Members. Journal Young Pharmacist 8: 487-491.

37. Scudder K, Blehm KD (1991) Household Hazardous Waste: Assessing public attitudes and awareness. Journal of Environmental Health 53: 18-20.

38. Selin H (2009) Managing Hazardous Chemicals: Longer-Range Challenges. Boston University.
39. Lunar BC, Padura VR, Dimaculangan CF (2014) Familiarity and Understanding of Chemical Hazard Warning Signs Among Select College Students of De La Salle Lipa. Asia Pacific Journal of Multidisciplinary Research 2: 99-102.

40. Economic Commission for Africa (2009) Africa Review Report on Chemicals. Sixth Session of the Committee on Food Security and Sustainable. Addis Ababa, Ethiopia.

41. Tyrkko K, Gaba M, Carvalho S, Der Veen HV, Jacobs M, et al. (2011) Chemicals and Gender United Nations Development Programme. February 2011.

42. International Labor Organization (2005) Prevention as a global strategy: The ILO Report for World Day for Safety and Health at Work Geneva, 2005.

43. Luca FA, Ciobanu CL, Andrei AG, Horodnic AV (2018) Raising Awareness on Health Impact of the Chemicals Used in Consumer Products: Empirical Evidence from East-Central Europe 10: 1-15.

44. Shafiei L, Taymoori P, Yazdanshenas K (2016) Awareness and attitude assessment regarding toxic metal-contaminated rice based on the Health Belief Model. J Adv Environ Health Res 4: 78-87.

45. Sexton K, Ryan AD, Adgate JL, Barr DB, Needham LL (2011) Biomarker measurements of concurrent exposure to multiple environmental chemicals and chemical classes in children. Journal of Toxicology and Environmental Health 74: 927-942.

46. Konradsen F, Van der Hoek W, Cole DC, Hutchinson G, Daisley H, et al. (2003) Reducing acute poisoning in developing countries-options for restricting the availability of pesticides. Toxicology 192: 249-261.

47. Khalid S, Shahid M, Bibi I, Sarwar T, Shah AH, et al. (2018) A Review of Environmental Contamination and Health Risk Assessment of Wastewater Use for Crop Irrigation with a Focus on Low and HighIncome Countries. International Journal of Environmental Research and Public Health 15: 1-36.

48. Hurtig AK, Sebastian S, Soto A, Shingre A, Zambrano D, et al. (2003) Pesticide use among farmers in the Amazon Basin of Ecuador. Arch Environ Health 58: 223-228.

49. World Health Organization (2004) Guidelines on the prevention of toxic exposures: Education and public awareness activities. Designed in New Zealand and Printed in France.

50. World Health Organization (1997) Guidelines for Poisons Control. World Health Organization, Geneva, Switzerland.

51. Murray CJ, Lopez AD (1997) Alternative projections of mortality and disability by cause 1990-2020: Global Burden of Disease Study. Lancet 349: 1498-1504.

52. Goldman L, Tran N (2002) Toxics and poverty: the impact of toxic substances on the poor in developing countries.

53. Lopes EJ, Okamura LA, Yamamoto CL (2015) Formation of Dioxins and Furans during Municipal Solid Waste Gasification. Brazilian Journal of Chemical Engineering 32: 87-97.

54. Swedish International Development Cooperation Agency (2017) Chemicals and Hazardous Waste. Sweden, Stockholm.

55. World Health Organization (2009) Global health risks: mortality and burden of diseases attributable to selected major risks Geneva. 